\section{Sensitivity and specificity of the body mass index for the diagnosis of overweight/ obesity in elderly}

\author{
Sensibilidade e especificidade do índice de massa \\ corporal no diagnóstico de sobrepeso/ \\ obesidade em idosos
}

\author{
1 Departamento de \\ Nutrição, Universidade \\ Federal de Santa Catarina, \\ Florianópolis, Brasil. \\ 2 Curso de Nutrição, \\ Universidade Estácio de Sá, \\ Florianópolis, Brasil. \\ 3 Programa de Pós-graduação \\ em Nutrição, Universidade \\ Federal de Santa Catarina, \\ Florianópolis, Brasil. \\ 4 Departamento de Educação \\ Física, Universidade Estadual \\ de Ponta Grossa, Ponta \\ Grossa, Brasil. \\ 5 Programa de Pós-graduação \\ em Educação Física, \\ Universidade Federal \\ de Santa Catarina, \\ Florianópolis, Brasil. \\ Correspondence \\ F. A. G. Vasconcelos \\ Departamento de Nutrição, \\ Universidade Federal de \\ Santa Catarina. \\ Rua Cap. Romualdo de \\ Barros 997, bloco B1 203, \\ Florianópolis, SC \\ 88040-600, Brasil. \\ fguedes@floripa.com.br
}

\begin{abstract}
The aim of this article was to verify the sensitivity and specificity of the body mass index (BMI) cut-off points proposed by the World Health Organization (WHO) and the Nutrition Screening Initiative (NSI) for the diagnosis of obesity in the elderly. A cross-sectional study was made with 180 healthy elderly subjects from Florianópolis, Santa Catarina State, Brazil. Body fat percentage (\%BF) was determined using DEXA (dual energy $X$-ray absorptiometry). The BMI cut-off point of the NSI offers better sensitivity and specificity for men $(73.7 \%$ and $72.5 \%$ respectively). For women, the lower the cut-off point the better the sensitivity, with a BMI of $25 \mathrm{~kg} / \mathrm{m}^{2}$ (sensitivity of $76.3 \%$ and specificity of 100\%) being the most accurate for diagnosing obesity in elderly women. The WHO cut-off point offered very low sensitivity (28.9\%). The results of this investigation lead to the conclusion that the cut-off points proposed by the WHO and the ones adopted by the NSI and by Lipschitz are not good indicators of obesity for the elderly of either sex, since they offer low sensitivity.
\end{abstract}

Body Mass Index; Sensitivity and Specificity; Overweight; Obesity; Aged
Francisco de Assis Guedes de Vasconcelos 1 Braian Alves Cordeiro 2,3 Cassiano Ricardo Rech 4 Edio Luiz Petroski 5

\section{Introduction}

The aging process causes nutritional, morphological and physiological modifications, such as reductions in height and body weight, reduction of fat-free mass and increase in fat mass 1,2,3.

The increase in fat mass, particularly in the trunk region, occurs especially after the age of 45 . It is related to the redistribution of fat mass, with a reduction of fat in the limbs being followed by an increase in trunk fat, due to hormonal factors 4,5 .

The aging process also affects men differently to women. Men have a smaller absolute loss of muscle mass when compared with elderly women. Elderly women, on the other hand, exhibit an increase in fat mass and a reduction in bone mass 6,7 .

Excessive fat mass may be defined as obesity, a chronic disease directly or indirectly related to other pathological situations which contribute to morbidity and mortality, such as cardiovascular, bone-muscular and neoplastic diseases 8 .

Nevertheless, the methods available for diagnosing obesity in the elderly are still not specific, considering the modifications in body composition which occur during the aging process. The most widely used method is the one proposed by the World Health Organization (WHO) 8 based on body mass index (BMI) for the adult population. According to this method, an individual is considered pre-obese when having a BMI equal to or above $25 \mathrm{~kg} / \mathrm{m}^{2}$ and below $30 \mathrm{~kg} / \mathrm{m}^{2}$ and obese 
when having a BMI equal to or above $30 \mathrm{~kg} / \mathrm{m}^{2}$, regardless of age or sex. It is worth emphasizing that these cut-off points for BMI were originally established based on the risk of developing associated morbidities or chronic diseases such as hypertension, high blood cholesterol, type 2 diabetes, coronary heart disease, and other diseases 8 .

In the 1990s, another classification based on BMI was proposed for the diagnosis of obesity, adapted to the elderly population. This classification is used by the Nutrition Screening Initiative (NSI) 9 and adopted by Lipschitz ${ }^{10}$, in which seniors with a BMI above $27 \mathrm{~kg} / \mathrm{m}^{2}$ are classified as overweight, while those with a BMI below $22 \mathrm{~kg} / \mathrm{m}^{2}$ are classified as thin. Lipschitz 10 says that the use of these values from the lesser mortality of the elderly in this BMI range, however, does not refer to changes of aging.

Some limitations, however, have been identified when using these diagnostic procedures with the elderly population, including studies conducted in Brazil 11,12,13. Lohman 14 points out that BMI can be influenced by muscle mass, organs, bone structure and fat mass. Therefore, an individual with great quantities of fat free mass could exhibit the BMI of an obese person, but not have excessive fat mass. Similarly, an individual with small bone structure or reduced muscular mass, but with a great quantity of fat mass, could be misclassified as normal (eutrofic) when actually overweight 14 .

Therefore, when the distinct changes to the body that occur in aging are taken into consideration, it is possible that two people with the same BMI may actually have different percentage fat mass 15 . This is why BMI should be specific for age groups and differentiated among populations and ethnic groups 16.

On the other hand, Lohman 14 states that the cut-off points for the diagnosis of obesity based on percentage body fat for adult population, which places an individual at risk is above $25 \%$ of body fat for men and $32 \%$ for women.

Considering the changes in body composition during aging and the importance of an accurate diagnosis of obesity in the elderly, the objective of this study was to verify the sensitivity and specificity of the BMI cut-off points proposed by WHO 8 and NSI 9 for diagnosing obesity in the elderly.

\section{Materials and methods}

This was a cross-sectional study. The sample was composed of 180 elderly subjects (60 men and 120 women), considered healthy or without evidence of serious chronic diseases, all of them living in the municipality of Florianópolis in the State of Santa Catarina, Southern Brazil, in 2005. Details about the development and design of the study have been described elsewhere 17,18. Briefly, the subjects were selected by invitation among participants of four elderly leisure groups. These groups were selected among people living close to the places where the measurements were carried out, thus avoiding major discomfort for the subjects.

A total of 266 elderly subjects ( 115 men and 151 women) were contacted by telephone and interviewed. 86 subjects (57 men and 29 women) did not fulfill the criteria for inclusion in the sample since they presented symptoms of high blood pressure, had some type of cancer, amputation and pacemaker, were younger than 60 years, were taking diuretics, had a fixed prosthesis or were not interested in participating in the study. During the telephone contact, the subjects also responded to a questionnaire regarding demographic and socioeconomic data and the dates for the anthropometric, dietetic, bioelectrical impedance and dual energy X-ray absorptiometry (DEXA) measurements were also scheduled 17,18.

Research was conducted according to the ethical principles regarding an individual's autonomy, as per Resolution n ${ }^{\circ}$. 196/96 of the National Health Council. The project was approved by the Human Research Ethics Committee at the Federal University of Santa Catarina (UFSC), under protocol no. 063/05.

Anthropometric measures (weight and height) were taken during the morning (between 8 and 10am), at the Physical Effort Laboratory, part of the UFSC Sports Center. All data were collected by one person, (with error of measurement of between $0.24 \%$ and $2.62 \% 19$ ), who had been given appropriate training in the techniques and standards employed 20. The BMI [weight $(\mathrm{kg}) /$ height $\left(\mathrm{m}^{2}\right)$ ] was classified by using two criteria: (1) the WHO cut-off points ${ }^{8}$, considering preobese those subjects with BMI above $25 \mathrm{~kg} / \mathrm{m}^{2}$ and below $30 \mathrm{~kg} / \mathrm{m}^{2}$; and obese those with BMI above $30 \mathrm{~kg} / \mathrm{m}^{2}$; (2) the cut-off point adapted for the elderly and used by the NSI 9 , whereby overweight individuals were considered to be those with a BMI above $27 \mathrm{~kg} / \mathrm{m}^{2}$.

Percentage body fat and fat free mass were measured by whole-body scanning with a Lunar Prodigy DF + 14.319 radiation densitometer (GE Medical, Madison, USA) using the DPX-L software version 7.52.002 (SONITEC, Florianópolis, Brazil) for quantification. During evaluation, each senior wore just an apron, was barefoot without earrings, rings, dental prosthetics or other materials, and was immobilized in dorsal decubitus, keeping the arms and legs away from 
the body. Each examination took around 10-15 minutes. The equipment was calibrated daily, according to the manufacturer's instructions. Evaluations were conducted by a technician in medical radiology, at the Diagnostic Imaging Center (SONITEC), in the city of Florianópolis, during the afternoon, between $4 \mathrm{pm}$ and $6.30 \mathrm{pm}$.

Both anthropometric and DEXA data were collected in two different hours on the same day, due to the distance between the places for data collection and the schedules offered by the clinic. This does not generate a bias, since there is no comparison between different methods of body fat percentage and there is no significant change in body composition in a few hours.

Data were analyzed using the SPSS, version 11.5 (SPSS Inc., Chicago, USA), adopting a level of significance of $\mathrm{p}<0.05$.

Student's t test for independent variables was used to compare age, weight, height, BMI and percentage of body fat between men and women and between obese and non-obese groups.

The sensitivity and specificity of the different cut-off points for obesity diagnosis using BMI were estimated. These tests are described as methods that are theoretically capable of indicating the presence or absence of a given disease, with a certain chance of error. The probability of a diagnostic test producing a positive result, when the individual does indeed have a given disease, is called test sensitivity; and the probability of the test producing a negative result, when the individual does not have the disease, is called specificity 21 .

In order to estimate sensitivity and specificity, it was necessary to create tables of crossed tabulation comparing the different cut-off points to reference values, based on percentage of body fat. For this procedure the percentage of body fat obtained by DEXA was adopted as gold standard for the diagnosis of obesity, according to various investigations made with the elderly population $1,6,15,22,23$. The values proposed by Lohman 14 for adult population, of $25 \%$ of body fat for men and $32 \%$ of body fat for women, was adopted as reference cut-offs.

To determine the most adequate BMI cut-off points for the diagnosis of obesity in the elderly, a statistic procedure known as ROC (receiver operating characteristic) curve was employed. In this procedure, the area under the curve (AUC) can be used to quantify how well a predictor discriminates between individuals with and without a disease ${ }^{24}$, with the disease in this case being obesity. The AUC was then calculated to determine the most sensitive and specific cut-off points for obesity in the population studied.

\section{Results}

Table 1 lists the physical characteristics of the elderly subjects in the form of descriptive statistics. The sample consisted of 180 healthy elderly subjects (60 men and 120 women) ranging in age from 60 to 81 years. Men had greater mean age, weight and height. The men and women had similar BMI values, but the difference between them was significant $(p<0.05)$. Women had higher percentages of body fat and had lower fat free mass than men, suggesting that sex can be an important variable in determining obesity cutoff points.

Table 1

Descriptive values (means and standard deviations - SD) of the physical characteristics of the elderly people investigated, by sex. Florianópolis, Santa Catarina State, Brazil, 2005.

\begin{tabular}{lcc}
\hline Variables & $\begin{array}{c}\text { Men }(\mathbf{n}=60) \\
\text { Mean } \pm \text { SD }\end{array}$ & $\begin{array}{c}\text { Women }(\mathbf{n}=120) \\
\text { Mean } \pm \text { SD }\end{array}$ \\
\hline Age (years) * & $69.14 \pm 5.6$ & $67.2 \pm 5.2$ \\
Weight $(\mathrm{kg})$ * & $74.3 \pm 10.7$ & $65.7 \pm 11.1$ \\
Height $(\mathrm{cm})$ * & $167.2 \pm 7.4$ & $154.5 \pm 5.7$ \\
BMI $\left(\mathrm{kg} / \mathrm{m}^{2}\right)$ * & $26.5 \pm 2.8$ & $27.4 \pm 3.9$ \\
Fat free mass [DEXA] $(\mathrm{kg})$ * & $54.9 \pm 6.8$ & $38.9 \pm 4.5$ \\
Percentage of body fat [DEXA] * & $23.02 \pm 5.8$ & $37.3 \pm 6.9$
\end{tabular}

BMI: body mass index; DEXA: dual energy X-ray absorptiometry.

* Significant difference between sexes $(p<0.05)$, Student's t test for independent variables.

According to a previous article 17 , an interesting socioeconomic demographic characteristic was that $60 \%(n=108)$ of the subjects were between 60 and 70 years of age, characterizing the sample as a young elderly population. Regarding marital status, $88.3 \%(\mathrm{n}=53)$ of men and $65 \%(n=78)$ of women were married. The educational level was considered to be above national standards: $42.8 \%$ of the elderly subjects had completed middle school or completed high school, and $57.2 \%$ had completed elementary school (until 8th grade). Most elderly subjects (84.3\%) performed some type of physical activity (more than twice a week). Men were found to be less active than women $\left(\mathrm{p}<0.05, \chi^{2}=2.35\right)$. The main activities reported by subjects practicing physical exercise were walking, localized gymnastics, working out, water gymnastics and dancing.

There was a higher prevalence of obesity among the women than among the men (Table 2 ), in all BMI categories and by percentage of 
Prevalence of obese and non-obese elderly people in the sample according to percentage of body fat and different body mass index (BMI) cut-off points, by sex. Florianópolis, Santa Catarina State, Brazil, 2005.

\begin{tabular}{|c|c|c|}
\hline Categories & Non-obese (\%) & Obese (\%) \\
\hline \multicolumn{3}{|l|}{$\operatorname{Men}(n=60)$} \\
\hline Percentage of body fat [DEXA] * & 67.8 & 32.2 \\
\hline $\mathrm{BMI} \geq 25 \mathrm{~kg} / \mathrm{m}^{2}$ ** & 28,8 & 71,2 \\
\hline 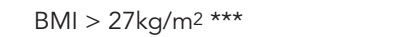 & 57.6 & 42.4 \\
\hline $\mathrm{BMI} \geq 30 \mathrm{~kg} / \mathrm{m}^{2} * *$ & 88.1 & 11.9 \\
\hline \multicolumn{3}{|l|}{ Women $(n=120)$} \\
\hline Percentage of body fat [DEXA] * & 4.2 & 95.8 \\
\hline $\mathrm{BMI} \geq 25 \mathrm{~kg} / \mathrm{m}^{2} * \star$ & 26.9 & 73.1 \\
\hline 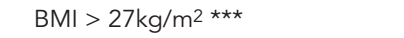 & 46.2 & 53.8 \\
\hline $\mathrm{BMI} \geq 30 \mathrm{~kg} / \mathrm{m}^{2} * \star$ & 72.3 & 27.7 \\
\hline
\end{tabular}

DEXA: dual energy X-ray absorptiometry.

* Considering the cut-off points proposed by Lohman 14 for diagnosis of obesity ( $25 \%$ for men and $32 \%$ for women);

** According to the World Health Organization 8;

$\star \star \star$ According to the Nutrition Screening Initiative ${ }^{9}$.

body fat. When determined by percentage of body fat measured by DEXA, $32.2 \%$ of the men were obese, against $95.8 \%$ of the women. When the WHO 8 cut-off point (BMI $\geq 30 \mathrm{~kg} / \mathrm{m}^{2}$ ) was used, $11.9 \%$ of the men and $27.7 \%$ of the women were considered obese. A total of $42.4 \%$ of the men were classified as obese when the NSI ${ }^{9}$ cutoff point $\left(\mathrm{BMI}>27 \mathrm{~kg} / \mathrm{m}^{2}\right)$ was used; for women, this percentage was $53.8 \%$. This shows that the prevalence of obesity was higher with the lower BMI cut-off points.

When different BMI cut-off points proposed by WHO 8 for diagnosing obesity were used, there was a difference between sexes only for those elderly with BMI less than $25 \mathrm{~kg} / \mathrm{m}^{2}$. When percentage of body fat was compared between sexes, the difference was not significant for any BMI category, but when mean of percentage of body fat values were compared in different categories for the same sex, a significant difference was detected $(\mathrm{p}<0.001)$. For the women, considering percentage of body fat by BMI categories, even those women whose BMI was between $25 \mathrm{~kg} / \mathrm{m}^{2}$ and $30 \mathrm{~kg} / \mathrm{m}^{2}$ had mean percentage of body fat above $32 \%$, classified as obesity for this sex. In contrast, only those men whose BMI was above $30 \mathrm{~kg} / \mathrm{m}^{2}$ were classified as obese by their percentage of body fat (data not shown).

Table 3 presents the sensitivity and specificity values for BMI cut-off points, according to fat mass measurement (DEXA) in elderly subjects of both sexes. For the men, the BMI values used by NSI ${ }^{9}$ and by Lipschitz 10 offered better sensitivity and specificity and can be considered the most accurate. The BMI value of $25 \mathrm{~kg} / \mathrm{m}^{2}$ offers high sensitivity (94.7\%), but low specificity $(40 \%)$, which translates into an increase in the amount of false-positives, that is, a higher prevalence of individuals wrongly diagnosed with obesity. A BMI of $30 \mathrm{~kg} / \mathrm{m}^{2}$ had low sensitivity (31.6\%), but high specificity (97.5\%), which translates into a high number of false-negatives, that is, a higher prevalence of individuals being misdiagnosed as normal (eutrofic) when in fact they are obese. With women, the lower the cut-off point, the better the sensitivity, bearing in mind that specificity did not change. In this case, a BMI of $25 \mathrm{~kg} / \mathrm{m}^{2}$ would be more accurate for diagnosing obesity in elderly women when compared to other values, exactly because it is the lowest value. The cut-off point for BMI of $30 \mathrm{~kg} / \mathrm{m}^{2}$ proposed by WHO 8 had very low sensitivity $(28.9 \%)$, causing a great number of people to be diagnosed as normal when they had excessive fat mass, or were obese, according to the DEXA gold standard.

The ROC curve is presented in Figures 1 and 2, as well as the corresponding AUC values.

In this study, the value of BMI with better sensitivity and specificity for men was $27.58 \mathrm{~kg} / \mathrm{m}^{2}$. This cut-off point provides a sensitivity of 73.7 (95\% confidence interval - 95\%CI: 48.8-90.8) and a specificity of 85.0 (95\%CI: 70.2-94.3). The value of BMI with better sensitivity and specificity for women was $22.89 \mathrm{~kg} / \mathrm{m}^{2}$. This cut-off point provides a sensitivity of 88.6 (95\%CI: 81.3-93.8) and a specificity of 100.0 (95\%CI: 48.0-100.0) (data not shown). 
Table 3

Sensitivity and specificity of body mass index (BMI) cut-off points in relation to fat mass measured by dual energy X-ray absorptiometry (DEXA) * in elderly of both sexes. Florianópolis, Santa Catarina State, Brazil, 2005.

\begin{tabular}{|c|c|c|c|c|}
\hline Categories & Sensitivity (\%) & Specificity (\%) & False-positives & False-negatives \\
\hline \multicolumn{5}{|l|}{ Men $(n=60)$} \\
\hline $\mathrm{BMI} \geq 25 \mathrm{~kg} / \mathrm{m}^{2} \star \star *$ & 94.7 & 40 & 24 & 1 \\
\hline $\mathrm{BMI}>27 \mathrm{~kg} / \mathrm{m}^{2} * * *$ & 73.7 & 72.5 & 11 & 5 \\
\hline $\mathrm{BMI} \geq 30 \mathrm{~kg} / \mathrm{m}^{2} * *$ & 31.6 & 97.5 & 1 & 13 \\
\hline \multicolumn{5}{|l|}{ Women $(n=120)$} \\
\hline 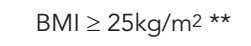 & 76.3 & 100.0 & 0 & 27 \\
\hline $\mathrm{BMI}>27 \mathrm{~kg} / \mathrm{m}^{2} * \star \star$ & 56.1 & 100.0 & 0 & 50 \\
\hline $\mathrm{BMI} \geq 30 \mathrm{~kg} / \mathrm{m}^{2}$ ** & 28.9 & 100.0 & 0 & 81 \\
\hline
\end{tabular}

* Considering the cut-off points proposed by Lohman 14 (25\% for men and $32 \%$ for women) as the gold standard for the diagnosis of obesity;

** According to the World Health Organization 8 ;

*** According to the Nutrition Screening Initiative 9.

Figure 1

Receiver operating characteristic (ROC) curve of body mass index (BMI) by percentage of body fat using dual energy X-ray absorptiometry (DEXA) of the elderly men investigated, $95 \%$ confidence interval $(95 \% \mathrm{Cl})$ for the area under the curve (AUC). Florianópolis, Santa Catarina State, Brazil, 2005

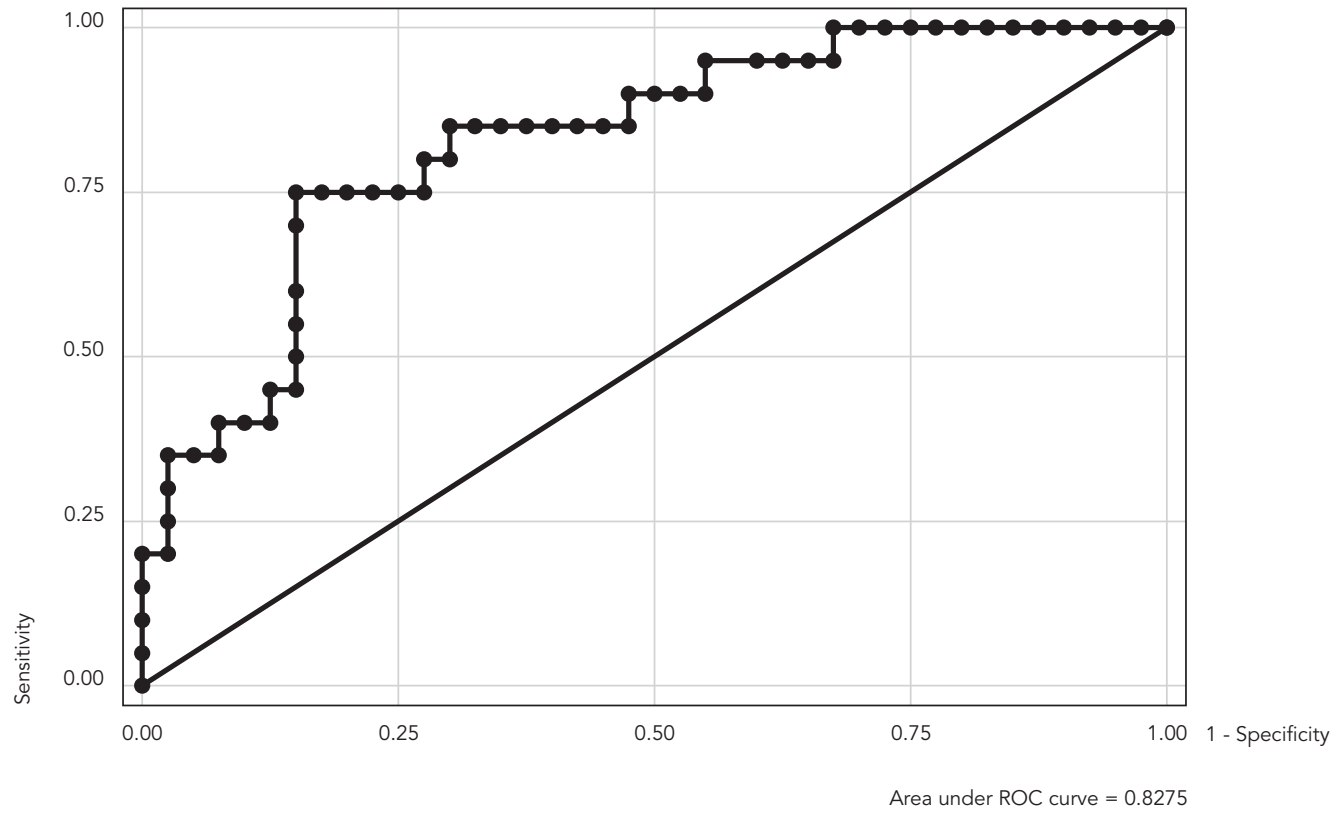


Receiver operating characteristic (ROC) curve of body mass index (BMI) by percentage of body fat using dual energy X-ray absorptiometry (DEXA) of the elderly women investigated, $95 \%$ confidence interval $(95 \% \mathrm{Cl})$ for the area under the curve (AUC). Florianópolis, Santa Catarina State, Brazil, 2005

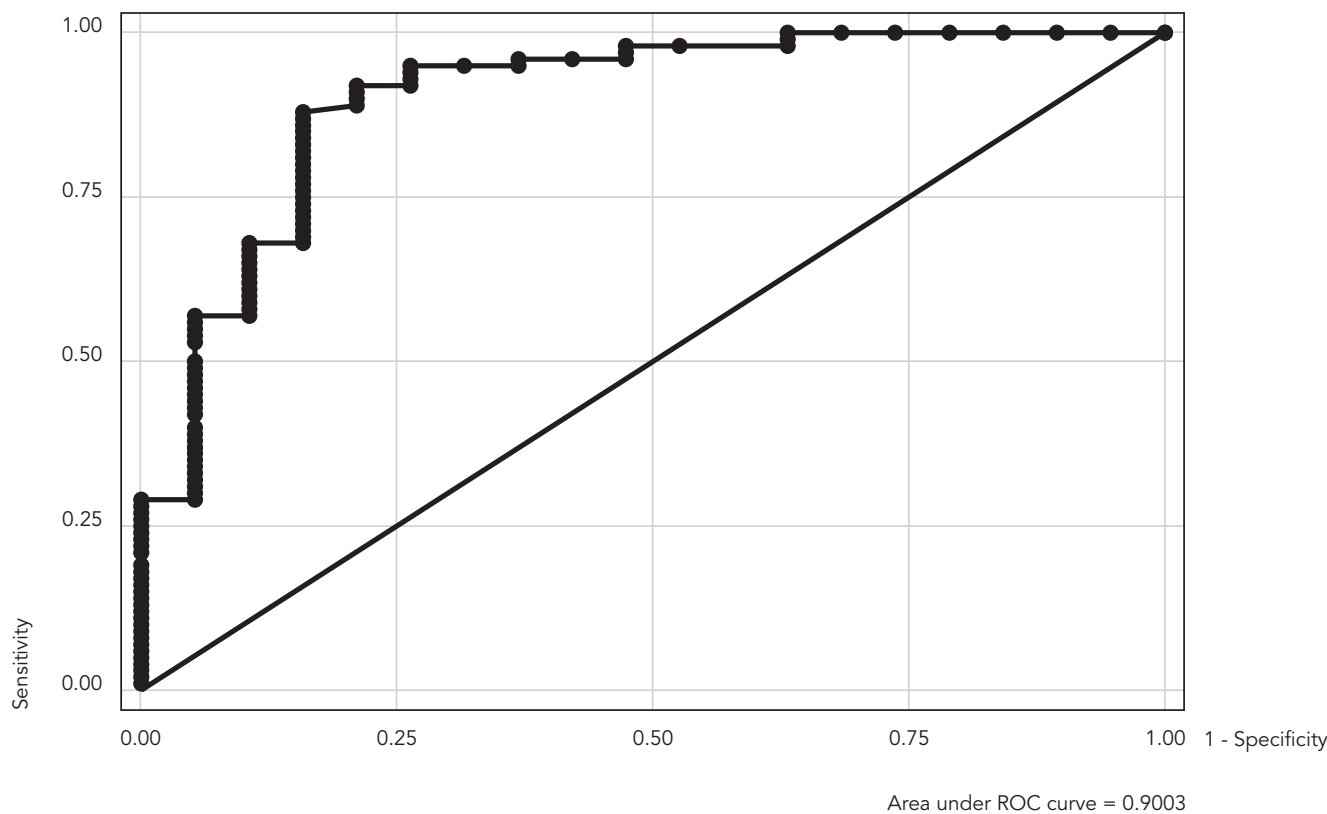

\section{Discussion}

In this study, significant differences in physical variables were observed between elderly men and women. Men had higher mean age, weight, height and fat free mass, and lower percentage of body fat, demonstrating that sex can be an important variable in the determination of cut-off points for obesity. Such differentiation between men and women, during aging, is common in the literature 6,7,11,12.

There was a significant difference $(\mathrm{p}<0.05)$ between the BMI values of the men and the women. The results of this study differ from those of Sampaio \& Figueiredo 25. In their study, conducted with 316 elderly subjects aged $70.5 \pm 7.5$ years (men) and $69.9 \pm 6.3$ years (women), they stated that there was no significant difference between the mean BMI values of elderly men and women.

Conversely, Santos et al. 26 , in a study conducted in Chile with 1,220 men and women aged between 60 and 99 years old, showed that men were heavier than women, but that the latter had higher BMI. Perissinotto et al. 2 conducted a study with 3,356 elderly Italians and found that BMI was significantly higher among the women than the men $\left(27.6 \pm 5.7 \mathrm{~kg} / \mathrm{m}^{2}\right.$ and $26.4 \pm 3.7 \mathrm{~kg} / \mathrm{m}^{2}$ respectively, $\mathrm{p}<0.001)$. There was a high prevalence of obesity, and higher values were observed among the women (28\% against $16 \%$ in men, respectively).

In this investigation, the prevalence of obese women was higher when compared to men, according to the BMI classification, in common with other authors' findings 2,26. Similar results were observed for the percentage of body fat measured by DEXA, comparable with findings published by Perissinotto et al. 2 .

Several studies have found evidence of the association of mortality with increased BMI values. For instance, Ajani et al. 27 reported (through multivariate analyses adjusted for age, alcohol intake and physical activity), that the relative risk for mortality directly increases when BMI values escalate. They claimed that, for all age strata analyzed (40-54, 55-69 and 70-84 years), even those who never smoked but had a BMI higher than $30 \mathrm{~kg} / \mathrm{m}^{2}$ had a death risk of approximately $70 \%$ when compared with groups with a BMI between 22.5 and $24.9 \mathrm{~kg} / \mathrm{m}^{2}$. 
Increased BMI values are also directly related to increased risk of developing cardiovascular diseases and mortality 28,29 .

Several authors have discussed the diagnosis of obesity based either on percentage of body fat or BMI. In a study by Kontogianni et al. 30, conducted with post-menopausal women, the BMI cut-off point for obesity ( $>30 \mathrm{~kg} / \mathrm{m}^{2}$ ) detected a prevalence of $30.6 \%$, while all participants $(\mathrm{n}=115)$ were classified as obese when the percentage of body fat criterion was used ( $>32 \%$ ). These results are similar to those presented in this article, where the prevalence of obese women, according to percentage of body fat was $95.8 \%$.

Regarding the possible variation of percentage of body fat among individuals with the same BMI values, Svendsen 31 compared subjects with BMI values of $25 \mathrm{~kg} / \mathrm{m}^{2}$ and observed that they exhibited a variation in percentage of body fat from $20 \%$ to $50 \%$.

Hortobágyi et al. 32 , in a study that analyzed BMI's sensitivity and specificity in the diagnosis of obesity in men and women with mean ages of $39.3 \pm 10.16$ and $38.8 \pm 10.54$ years of age, respectively, detected that only $28 \%$ of men were classified as obese according to BMI, but $42 \%$ according to percentage of body fat. In women, $12 \%$ were diagnosed as obese by the BMI, and $40 \%$ according to percentage of body fat.

Sardinha \& Teixeira 15 , in a study conducted with women aged $60.5 \pm 7.1$ years and using as cut-off points values above $35 \%$ of body fat to determine obesity, showed that mean BMI was of $27.8 \pm 4.2 \mathrm{~kg} / \mathrm{m}^{2}$ and the mean percentage of body fat was $42.6 \%$. If we consider the sample used by these authors, the mean BMI would classify this population as pre-obese, while the percentage of body fat would define it as obese.

The data presented in this article show that mean BMI of the men was $26.5 \pm 2.8 \mathrm{~kg} / \mathrm{m}^{2}$ and for the women it was $27.4 \pm 3.9 \mathrm{~kg} / \mathrm{m}^{2}$. These BMI values would classify this population as pre-obese, according to the WHO 8 criterion, but when analyzed by percentage of body fat 14 , men would be diagnosed as non-obese ( $23.02 \pm 5.8 \%)$, while the women would be classed as obese $(37.3 \pm 6.9 \%)$.

In this study, when the cut-off point for BMI > $30 \mathrm{~kg} / \mathrm{m}^{2}$ proposed by the WHO 8 for the diagnosis of obesity was used, a sensitivity of $28.9 \%$ was obtained for women. Similar results were found by Sardinha \& Teixeira 15 , where the same point presented a sensitivity of $26.8 \%$, considered low by the authors, since it represented a high proportion of false-negatives (73.2\%). That study differed from this one in terms of the population studied and the percentage of body fat adopted (35\%), and it is probably because of this that their sensitivity values were not even more similar.
Smalley et al. 33, in 1990, had already stated that the problem with BMI rests in the sensitivity of the method, since only $55.4 \%$ of women and $44.3 \%$ of men studied were correctly diagnosed as obese according to BMI, when compared to percentage of body fat. Their study comprised 213 women and 150 men aged 15-68 and 18-82 years old, respectively.

According to Goh et al. 16, the cut-off point for BMI proposed by the WHO ${ }^{8}$ should be specific for each age group and population, since it presents low sensitivity (6.7\%) and specificity (13.4\%) indexes for diagnosing obesity in Asian populations.

Sensitivity and specificity were also analyzed by Blew et al. 22 According to these authors, in a study conducted with a population of postmenopausal women aged $54.8 \pm 4.8$ years, the most accurate BMI cut-off point for the diagnosis of obesity was $24.9 \mathrm{~kg} / \mathrm{m}^{2}$. In this study, the values of BMI with better sensitivity and specificity for women and men were $22.89 \mathrm{~kg} / \mathrm{m}^{2}$ and $27.58 \mathrm{~kg} / \mathrm{m}^{2}$, respectively.

Other authors have observed that the percentages of body fat to define overweight and obesity vary with age, being necessary to establish specific cut-off points for different stages of life ${ }^{34}$. Besides this, ethnic and cultural differences should also be considered, since they can be associated with BMI and percentage of body fat variables and may lead to misclassification of obesity and, consequently, of health prognosis 35 .

The results of this investigation allow for the conclusion that the cut-off points proposed by the WHO 8 and the ones adopted by NSI 9 and by Lipschitz 10 are not good indicators of obesity for the elderly of either sex, since they offer low sensitivity. Such low sensitivity would not classify as obese a great number of individuals with elevated percentage of body fat and, consequently, at risk of developing the pathologies associated.

In Brazil, the cut-off points for BMI established by the Ministry of Health for the elderly population are based on values recommended by Lipschitz 10 . The results of this research, although similar to those recommended by Ministry of Health, indicate that caution is needed in the use of diagnostic criteria of obesity in the elderly population. Thus, from the viewpoint of public policies aimed at meeting the nutritional needs of the elderly population, we suggest a revision of such criteria, particularly in relation to the difference observed between the sexes.

Therefore, we affirm the need to develop and validate new BMI criteria for diagnosis of obesity in the elderly. 


\section{Resumo}

O objetivo foi verificar a sensibilidade e especificidade dos pontos de corte do índice de massa corporal (IMC) propostos pela Organização Mundial da Saúde (OMS) e Nutrition Screening Initiative (NSI) no diagnóstico da obesidade em idosos. O estudo foi realizado com 180 idosos de Florianópolis, Santa Catarina, Brasil. O percentual de gordura corporal foi mensurado por absortometria radiológica de dupla energia. O IMC da NSI apresenta melhores valores de sensibilidade e especificidade para homens $(73,7 \%$ e $72,5 \%$ respectivamente). Para os homens o IMC de $25 \mathrm{~kg} / \mathrm{m}^{2}$ apresentou elevada sensibilidade $(94,7 \%)$ e baixa especificidade (40\%), enquanto o IMC de $30 \mathrm{~kg} / \mathrm{m}^{2}$ possui baixa sensibilidade (31,6\%) e elevada especificidade (97,5\%). Nas mulheres, o IMC de 25kg/m² (sensibilidade de 76,3\% e especificidade de 100\%) foi o mais acurado. O ponto de corte da OMS mostrou sensibilidade muito baixa $(28,9 \%)$. Os resultados desta investigação permitem concluir que os pontos de corte propostos pela OMS e NSI não são bons indicadores de sobrepeso/obesidade para idosos de ambos os sexos.

Índice de Massa Corporal; Sensibilidade e Especificidade; Sobrepeso; Obesidade; Idoso

\section{References}

1. Barbosa AL, Santarém JM, Jacob Filho W, Meirelles ES, Marucci MFN. Comparação da gordura corporal de mulheres idosas segundo antropometria, bioimpedância e DEXA. Arch Latinoam Nutr 2001; 51:49-56.

2. Perissinotto E, Pisent C, Sergi G, Grigolettol F, Enzi G. Anthropometric measurements in the elderly: age and gender differences. Br J Nutr 2002; 87:177-86.

3. França AP, Aldrighi JM, Marucci MFN. Fatores associados à obesidade global e à obesidade abdominal em mulheres na pós-menopausa. Rev Bras Saúde Matern Infant 2008; 8:65-73.

4. Horani MHE, Mooradian AD. Management of obesity in the elderly. Treat Endocrinol 2002; 1:387-98.

5. Steen B. Body composition and aging. Nutr Res 1988; 46:18-23.

\section{Contributors}

F. A. G. Vasconcelos and E. L. Petroski took the lead in planning the study, participated in designing the study and critically reviewed all parts of the paper. B. A. Cordeiro and C. R. Rech participated in designing the study, protocol execution, and interpretation of the results, besides writing the paper.

\section{Acknowledgments}

We are grateful to the elderly people who took part in this investigation, to the Santa Catarina State Science and Technology Research Support Foundation (FAPESC) for financial support and to the Diagnostic Imaging Center (SONITEC) for material support and to Professors Maria de Fátima Nunes Marucci and Tânia Bertoldo Benedetti, for their relevant criticism and contributions.
6. Kyle UG, Genton L, Hans D, Pichard C. Validation of a bioelectrical impedance analysis equation to predict appendicular skeletal muscle mass (ASMM). Clin Nutr 2003; 22:537-43.

7. Barrera G, Salazar G, Albala C, Vio F, Yañez M, Aicardi V, et al. Métodos de estimación de la composición corporal en ancianos: análisis crítico. Rev Méd Chile 1996; 124:1232-9.

8. World Health Organization. Obesity: preventing and managing the global epidemic. Report of a WHO Consultation on Obesity. Geneva: World Health Organization; 1998.

9. Nutrition Screening Initiative. Nutrition interventions manual for professionals caring for older Americans. Washington DC: Nutrition Screening Initiative; 1992. 
10. Lipschitz DA. Screening for nutritional status in the elderly. Prim Care 1994; 21:55-67.

11. Santos DM, Sichieri R. Índice de massa corporal e indicadores antropométricos de adiposidade em idosos. Rev Saúde Pública 2005; 39:163-8.

12. Silveira EA, Kac G, Barbosa LS. Prevalência e fatores associados à obesidade em idosos residentes em Pelotas, Rio Grande do Sul, Brasil: classificação da obesidade segundo dois pontos de corte do índice de massa corporal. Cad Saúde Pública 2009; 25:1569-77.

13. Garcia ANM, Romani SAM, Lira PIC. Indicadores antropométricos na avaliação nutricional de idosos: um estudo comparativo. Rev Nutr 2007; 20:371-8.

14. Lohman TG. Advances in body composition assessment. Champaign: Human Kinetics Books; 1992. (Current Issues in Exercise Science Series. Monograph, 3).

15. Sardinha LB, Teixeira PJ. Obesity screening in older women with body mass index: a receiver operating characteristic (ROC) analysis. Sci Sports 2000; 15:212-9.

16. Goh VHH, Tain CF, Tong TYY, Mok HPP, Wong T. Are BMI and other anthropometric measures appropriate as indices for obesity? A study in an Asian population. J Lipid Res 2004; 45:1892-8.

17. Rech CR, Cordeiro BA, Petroski EL, Vasconcelos FAG. Validation of bioelectrical impedance for the prediction of fat-free mass in Brazilian elderly subjects. Arq Bras Endocrinol Metab 2008; 52:1163-71.

18. Rech CR, Cordeiro BA, Petroski EL, Vasconcelos FAG. Utilização da espessura de dobras cutâneas para a estimativa da gordura corporal em idosos. Rev Nutr 2010; 23:17-26.

19. Norton K, Olds T. Antropométrica. Porto Alegre: Editora Artmed; 2005.

20. Gordon CC, Chumlea WC, Roche AF. Stature, recumbent length, weight. In: Lohman T, Roche A, Martorell R, editors. Anthropometric standardizing reference manual. Champaign: Human Kinetics Books; 1988. p. 3-8.

21. Martinez EZ, Louzada-Neto FL, Pereira BB. A curva ROC para testes diagnósticos. Cad Saúde Colet (Rio J.) 2003; 11:7-31.

22. Blew RM, Sardinha LB, Milliken LA, Teixeira PJ, Going SB, Ferreira DL, et al. Assessing the validity of body mass index standards in early postmenopausal women. Obes Res 2002; 10:799-808.

23. Salamone LM, Fuerst T, Visser M, Kern M, Lang T, Dockrell M, et al. Measurements of fat mass using DEXA: a validation study in elderly adults. J Appl Physiol 2000; 89:345-52.
24. Kirkwood BR, Sterne JAC. Medical statistics. 2nd Ed. Malden: Blackwell Science; 2003.

25. Sampaio LR, Figueiredo VC. Correlação entre o índice de massa corporal e os indicadores antropométricos de distribuição de gordura corporal em adultos e idosos. Rev Nutr 2005; 18:53-61.

26. Santos JL, Albala C, Lera L, García C, Arroyo P, Pérez-Bravo F, et al. Anthropometric measurements in the elderly population of Santiago, Chile. Nutrition 2004; 20:452-7.

27. Ajani UA, Lotufo PA, Gaziano JM, Lee IM, Spelsberg A, Buring JE, et al. Body mass index and mortality among US male physicians. Ann Epidemiol 2004; 14:731-9.

28. Harris TB, Ballard-Barbasch R, Madans J, Makuc DM, Feldman JJ. Overweight, weight loss and risk of coronary heart disease in older women. The NHANES I Epidemiologic Follow-up Study. Am J Epidemiol 1993; 137:1318-27.

29. Harris TB, Launer LJ, Madans J, Feldman JJ. Cohort study of effect of being overweight and change in weight on risk of coronary artery disease in old age. BMJ 1997; 314:1791-4.

30. Kontogianni MD, Panagiotakos DB, Skopouli FN. Does body mass index reflect adequately the body fat content in perimenopausal women? Maturitas 2005; 51:307-13.

31. Svendsen OL. Should measurement of body composition influence therapy for obesity? Acta Diabetol 2003; 40:250-3.

32. Hortobágyi T, Israel RG, O’Brien KF. Sensitivity and specificity of the Quetelet Index to assess obesity in men and women. Eur J Clin Nutr 1994; 48: 369-75.

33. Smalley KJ, Knerr AN, Kendrick ZV, Colliver JA, Owen OE. Reassessment ob body mass indices. Am J Clin Nutr 1990; 52:405-8.

34. Movsesyan L, Laszlo B, Philip JL, Christiansen C, Svendsen OL. Variations in percentage of body fat within different BMI groups in young, middle-aged and old women. Clin Physiol Funct Imaging 2003; 23:130-3.

35. Gallagher D, Ruts E, Visser M, Heshka S, Baumgartner RN, Wang J, et al. Weight stability masks sarcopenia in elderly men and women. Am J Physiol Endocrinol Metab 2000; 279:E366-75.

Submitted on $17 /$ Sep/2009

Final version resubmitted on 12/Mar/2010

Approved on 03/Mar/2010 